Since January 2020 Elsevier has created a COVID-19 resource centre with free information in English and Mandarin on the novel coronavirus COVID-19. The COVID-19 resource centre is hosted on Elsevier Connect, the company's public news and information website.

Elsevier hereby grants permission to make all its COVID-19-related research that is available on the COVID-19 resource centre - including this research content - immediately available in PubMed Central and other publicly funded repositories, such as the WHO COVID database with rights for unrestricted research re-use and analyses in any form or by any means with acknowledgement of the original source. These permissions are granted for free by Elsevier for as long as the COVID-19 resource centre remains active. 


\title{
Lung Pathology of Severe Acute Respiratory Syndrome (SARS): A Study of 8 Autopsy Cases From Singapore
}

\author{
TERI J. FRANKS, MD, PEK Y. CHONG, MBBS, FRCPA, \\ PAUL CHUI, MBBS, MRCPATH (FORENSIC), JEFFREY R. GALVIN, MD, \\ RAINA M. LOURENS, BS, ANN H. REID, MA, ELENA SELBS, MD, PHD, \\ COL PETER L. MCEVOY, MC USA, COL DENNIS L. HAYDEN, MC USA, \\ JUNYA FUKUOKA, MD, JEFFERY K. TAUBENBERGER, MD, PHD, \\ AND WILLIAM D. TRAVIS, MD
}

Severe acute respiratory syndrome (SARS) is an infectious condition caused by the SARS-associated coronavirus (SARS-CoV), a new member in the family Coronaviridae. To evaluate the lung pathology in this life-threatening respiratory illness, we studied postmortem lung sections from 8 patients who died from SARS during the spring 2003 Singapore outbreak. The predominant pattern of lung injury in all 8 cases was diffuse alveolar damage. The histology varied according to duration of illness. Cases that were 10 or fewer days in duration demonstrated acute phase diffuse alveolar damage (DAD), airspace edema, and bronchiolar fibrin. Cases with a time course greater than 10 days showed organ-

From the Department of Pulmonary and Mediastinal Pathology, Department of Radiologic Pathology, Division of Molecular Pathology, Department of Cellular Pathology and Genetics, and Division of Tropical and Infectious Disease Pathology, Department of Tropical and Infectious Diseases, Armed Forces Institute of Pathology, Washington, DC, USA; Department of Pathology and Laboratory Medicine, Tan Tock Seng Hospital, Singapore; Center for Forensic Medicine, Health Sciences Authority, Singapore

Address correspondence to Teri J. Franks, MD, Department of Pulmonary and Mediastinal Pathology, Armed Forces Institute of Pathology, $682516^{\text {th }}$ Street NW, Bldg. 54, Room M003B, Washington, DC 20306.

This is a US government work. There are no restrictions on its use.

0046-8177/03/3407-0017\$0.00/0

doi:10.1016/S0046-8177(03)00365-4 izing phase DAD, type II pneumocyte hyperplasia, squamous metaplasia, multinucleated giant cells, and acute bronchopneumonia. In acute $\mathrm{DAD}$, pancytokeratin staining was positive in hyaline membranes along alveolar walls and highlighted the absence of pneumocytes. Multinucleated cells were shown to be both type II pneumocytes and macrophages by pancytokeratin, TTF-1, and CD68 staining. SARS-CoV RNA was identified by RT-PCR in 7 of 8 cases in fresh autopsy tissue and in 8 of 8 cases in formalin-fixed, paraffin-embedded lung tissue including the one negative case in fresh tissue. Understanding the pathology of DAD in SARS patients may provide the basis for therapeutic strategies. Further studies of the pathogenesis of SARS may reveal new insights into mechanisms of DAD.

Key words: severe acute respiratory syndrome, SARS, SARS-associated corona virus, diffuse alveolar damage.

Abbreviations: SARS, severe acute respiratory syndrome; SARS-CoV, SARS-associated coronavirus; DAD, diffuse alveolar damage; RT-PCR, reverse transcriptase-polymerase chain reaction.

\section{Editor's Comment}

This well-documented autopsy-based study of severe acute respiratory syndrome (SARS) provides excellent documentation of the role of diffuse alveolar damage in the clinical manifestations of this highly infectious entity. The complete study with illustrations will appear in the August 2003 issue of Human Pathology.

\section{CORRESPONDENCE}

\section{Prostate Gland Differentiation in Females}

To the Editor:-I read with great interest Cohen et al's ${ }^{1}$ description of periurethral minor prostatic glands and of prostatic differentiation in glandular cystitis in male patients. The authors did not find similar prostate-specific antigen (PSA)-positive glands in females. They stated that female paraurethral glands of Skene do not show prostatic differen- tiation, in contrast to male periurethral glands. However, prostatic features have been described in Skene's glands. ${ }^{2-4}$ These glands produce various enzymes that are otherwise typical of the male prostate gland, and they also express PSA. Therefore, the term "female prostate" has been proposed. To support this concept, prostatic adenocarcinomas have been observed in female patients. ${ }^{4,5}$ Because the female prostate does exist, one should expect that minor prostatic glands can 